\title{
I dentifikasi Perubahan Garis Pantai dan Ekosistem Pesisir di Kabupaten Subang
}

\author{
DI AN N. HANDI ANI, SONI DARMAWAN, RI KA HERNAWATI, \\ MUHAMMAD F. SURYAHADI, YOHANES D. ADI TYA
}

\author{
Jurusan Teknik Geodesi \\ FTSP - Institut Teknologi Nasional, Bandung \\ Email: ddhandiani@itenas.ac.id
}

\begin{abstract}
ABSTRAK
Penelitian ini adalah kajian awal dari valuasi ekonomi atas manfaat dan jasa ekosistem di pesisir Subang. Faktor-faktor utama dalam valuasi adalah keberadaan ekosistem dan perubahan di pesisir, serta manfaat dan jasa ekosistemnya. Estimasi perubahan garis pantai dihitung berdasarkan tumpang susun data satelit Landsat tahun 1988, 1996, 2003, dan 2016. Estimasi menunjukkan terjadi perubahan garis pantai sebesar 8,17 km sejak tahun 1988-2013. Perubahan tersebut didominasi oleh sedimentasi dan abrasi sepanjang pantai. Sedimentasi tertinggi terjadi di Kecamatan Pusakanagara (869, 9 ha) dan Blanakan (725,4 ha), serta abrasi tertinggi terjadi di Kecamatan Legonkulon (885,8 ha). Ekosistem alami yang berubah dan dimanfaatkan secara intensif di pesisir Subang adalah kawasan estuari dan mangrove. Sehingga mengakibatkan penurunan fungsi ekologi pada ekosistem tersebut. Adapun lahan tambak sebagai ekosistem buatan yang menggantikan kawasan mangrove, hanya berfungsi sebagai penyedia kebutuhan pangan. Penelitian ini menunjukkan perlunya valuasi ekonomi atas lahan mangrove versus budidaya tambak di Kecamatan Legonkulon, serta kawasan estuari yang berfungsi sebagai sarana transportasi di Kecamatan Pusakanagara.
\end{abstract}

Kata kunci: garis pantai, ekosistem pesisir, erosi, sedimentasi, Subang

\begin{abstract}
This research is a preliminary study for economic valuation of coastal services and goods in Subang Regency. Main factors in the valuation are ecological existing, changing, services and goods of coastal ecosystem. Coastline changes estimation was based on the overlay of Landsat satellite image at year of 1988, 1996, 2003, and 2016. Estimation shows since year of 1988 to 2013 there is changing of coastline around $8,17 \mathrm{~km}$. The changes are dominantly caused by coastline sedimentation and abrasion. Higher sedimentation occured in Pusakanagara $(869,9$ ha) and Blanakan $(725,4)$ Subdistrict, while highest abrasion occured in Legonkulon (885,8 ha) Subdistrict. Estuary and mangrove forests are natural ecosystem that had been used intensively and changing very excessively in this region. These changing causes degradation in functions of these ecosystems. Meanwhile, changing of mangrove forest into aquaculture only provides food. This research shows the necessity in economic valution of mangrove forest versus aquaculture in Legonkulon Subdistrict, and also estuary as transportation function in Pusakanagara Subdistrict.
\end{abstract}

Keywords: coastline, coastal ecosystem, erosion, sedimentation, Subang 


\section{Pendahuluan}

Wilayah Pesisir Subang memiliki luas $13.380,27$ ha (DKP Subang, 2003) dan garis pantai sepanjang 48,20 km (Bappeda Subang, 2010). Aktivitas perekonomian di wilayah tersebut berpusat pada perikanan dan perdagangan dan memberikan tekanan berat pada lingkungan sekitarnya. Contohnya dalam perikanan, pembukaan lahan mangrove menjadi tambak yang menurut data telah dimanfaatkan sebagai tambak sebesar $80 \%$, melebihi kondisi ideal konversi mangrove yaitu 25\% (Fahrudin, 1996). Selanjutnya pembangunan perekonomian terkait transportasi: aktivitas pelabuhan, jalur keluar/masuk kapal, bongkar muat barang, dan aktivitas lainnya.

Ekosistem pesisir Subang memiliki nilai dan manfaat ekonomi maupun ekologi yang tinggi. Serta variasi ekosistemnya terbagi menjadi hutan mangrove, terumbu karang, estuari, padang lamun, dan lahan tambak (Kabupaten Subang, 2014). Saat ini Pesisir Subang telah mengalami degradasi ekologi yang mengakibatkan kerugian ekonomi (Saridewi, 2003). Jika penurunan kualitas dan kuantitas ekosistem di pesisir terus berlanjut akan mengancam kehidupan masyarakat setempat.

Pengelolaan wilayah pesisir berupaya meminimalisir degradasi lingkungan yang terjadi. Salah satu upayanya adalah melakukan pembangunan pesisir secara berkelanjutan. Perencanaan pengelolaan pesisir di Indonesia menerapkan keterpaduan antara kondisi biofisik dan pemanfaatan pesisir, serta skenario pengelolaan berbasis ekosistem yang dianalisa dalam berbagai dimensi waktu (Dahuri dkk., 1996; Diposaptono, 2016). Salah satu isu pengelolaan wilayah pesisir terpadu adalah kurang tepatnya informasi terkait penilaian ekonomi atas manfaat barang dan jasa di pesisir (Dahuri dkk., 1996; Fauzi, 2004). Informasi ini dibutuhkan oleh pemerintah maupun para pelaku ekonomi untuk bisa mengkuantifikasi secara nominal (hitungan rupiah) nilai perubahan sumberdaya ekosistem di pesisir.

Penelitian ini merupakan kajian awal bagi valuasi ekonomi atas perubahaan fungsi berbagai ekosistem di Pesisir Subang. Valuasi ekonomi dapat dihitung dengan mempertimbangkan nilai dan manfaat dari fungsi ekosistem tersebut. Nilai dan manfaat diketahui berdasarkan fungsi ekosistem dalam tata ruang (Dahuri dkk., 1996; Diposaptono, 2016). Perubahan tata ruang dan ekosistem pesisir dikaji berdasarkan spasial analisis dengan menganalisis perubahan garis pantai. Perubahan garis pantai diestimasi menggunakan pengindraan jauh dengan memanfaatkan data citra Landsat. Asumsi maju dan mundurnya garis pantai digunakan sebagai basis untuk mengetahui terjadinya sedimentasi dan abrasi di pesisir Subang. Selain itu pengumpulan data sekunder dari pihak terkait dan beberapa data primer di lapangan juga menjadi sumber dalam kajian.

Kajian ini bertujuan mengidentifikasi ekosistem di Pesisir Subang dan mendeskripsikan manfaatnya. Hasilnya menjadi input dalam penilaian ekonomi total terhadap perubahan ekosistem di Pesisir Subang, sehingga valuasi yang dilakukan nanti akan lebih efisien dan optimal. Selain itu hasil kajian ini memberikan infomasi bagi pihak pembuat kebijakan dalam pengelolaan ekosistem pesisir. 


\section{METODOLOGI}

\subsection{Tempat Penelitian}

Kajian dilakukan di pesisir utara Pulau Jawa di Pesisir Kabupaten Subang yang terdiri atas empat kecamatan: Blanakan, Sukasari, Legonkulon, dan Cipunagara (gambar 1). Wilayah ini terbagi menjadi empat kecamatan yaitu Blanakan, Legonkulon, Sukasari, dan Cipunagara yang merupakan tempat bermuaranya beberapa Daerah Aliran Sungai (DAS): Sungai Cilamaya, Blanakan, Ciasem, dan Cipunagara (Kabupaten Subang, 2014). Beberapa lokasi pengamatan di lapangan untuk kondisi sedimentasi di Kecamatan Pusakanagara dan abrasi di Kecamatan Legonkulon dan Blanakan (gambar 1a-c).

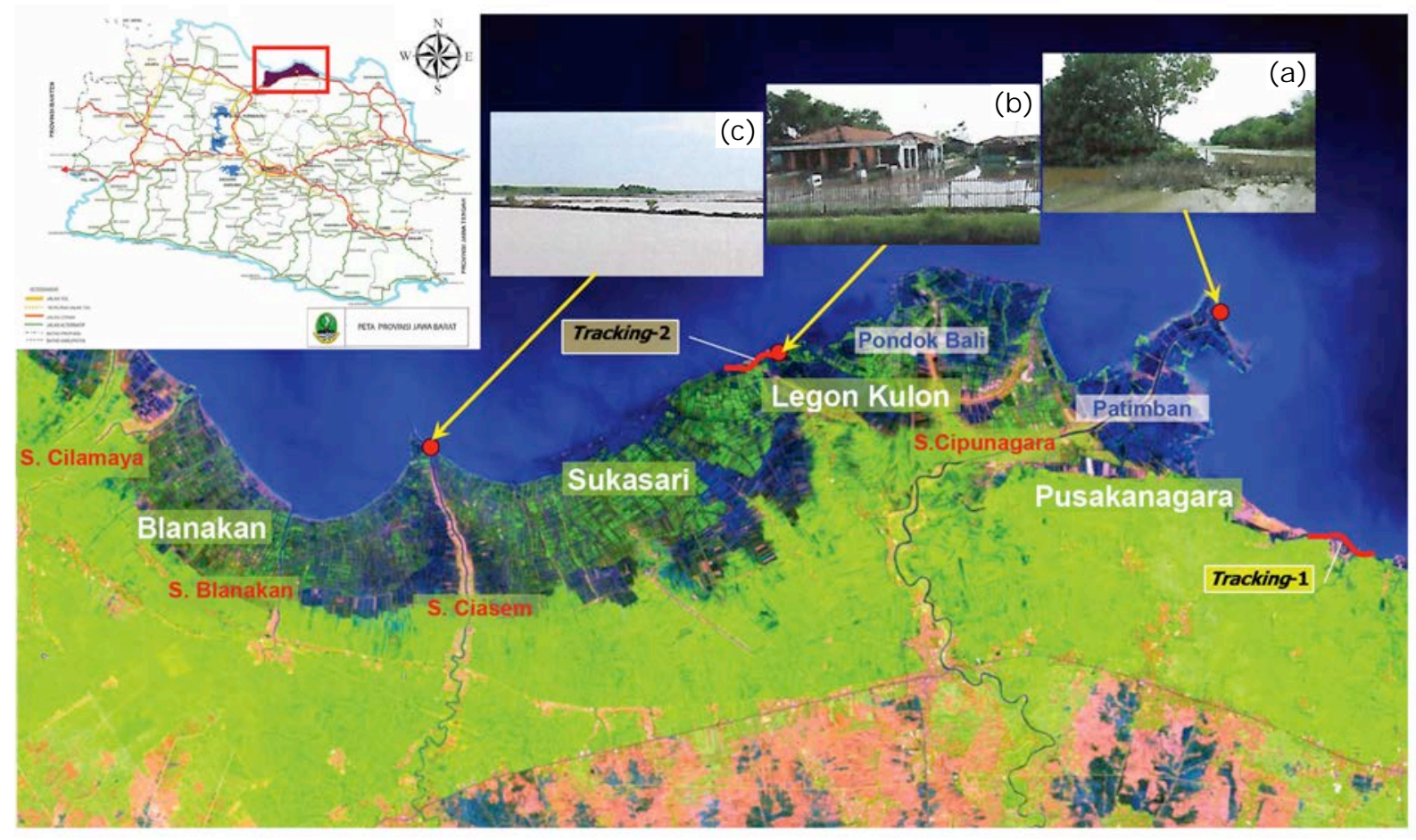

Gambar 1. Lokasi kajian dan pengamatan lapangan (a) sedimentasi di Pusakanagara, (b) abrasi di Legonkulon, dan (c) sedimentasi di Blanakan (Sumber: Pemprov Jabar, 2017; Darmawan dkk., 2016)

\subsection{Pengumpulan Data}

Data yang dikumpulkan dalam kajian ini berupa data primer dan sekunder (tabel 1). Data primer dikumpulkan melalui pengamatan kondisi lingkungan di lapangan melalui pengambilan gambar, pengisian kuesioner dan wawancara langsung dengan masyarakat sekitar. Penyusuran garis pantai (tracking 1 dan 2) di dua kecamatan Pusakanagara dan Legonkulon juga termasuk dalam data primer (gambar 1). Pemilihan lokasi responden untuk sampel kuesioner dan wawancara langsung dilakukan sesuai dengan tujuan yang jelas (purposive).

Data sekunder umumnya diperoleh dari berbagai kajian terkait pesisir Subang. Selain itu juga memanfaatkan data dari Badan Pusat Statistik Kabupaten Subang dan Badan Pengelolaan Lingkungan Hidup Daerah Jawa Barat (BPLHD Jabar). Data citra yang digunakan 
dalam analisis adalah citra Landsat 5 TM tahun 1988, 1996, 2003, dan citra Landsat 8 OLI tahun 2016. Semua data citra diunduh dari USGS Global Visualization Viewer (2017).

Tabel 1. Jenis dan Sumber Data yang Digunakan dalam Penelitian

\begin{tabular}{|c|c|c|c|}
\hline \multirow{2}{*}{ Tujuan } & \multirow{2}{*}{ Komponen Data } & \multicolumn{2}{|c|}{ Sumber Data } \\
\hline & & Primer & Sekunder \\
\hline $\begin{array}{l}\text { Mengidentifikasi garis pantai } \\
\text { serta mengestimasi luas } \\
\text { abrasi dan sedimentasi }\end{array}$ & $\begin{array}{l}\text { - Panjang garis pantai } \\
\text { - Luas sedimentasi dan abrasi }\end{array}$ & $\begin{array}{l}\text { Pengamatan di } \\
\text { lapangan: } \\
\text { - tracking/menyu- } \\
\text { suri pantai, } \\
\text { - responden }\end{array}$ & $\begin{array}{l}\text { - Citra Landsat } \\
\text { - Literatur }\end{array}$ \\
\hline Mengidentifikasi ekosistem & $\begin{array}{l}\text { Ekosistem Pesisir:Terumbu } \\
\text { karang, Padang lamun, } \\
\text { Estuari, Mangrove, dan } \\
\text { Tambak }\end{array}$ & - & $\begin{array}{l}\text { - BPLHD Jabar } \\
\text { - BPS Kab. Subang } \\
\text { - Literatur }\end{array}$ \\
\hline $\begin{array}{l}\text { Mendeskripsikan manfaat } \\
\text { yang didapatkan dari } \\
\text { ekosistem }\end{array}$ & Jenis pemanfaatan ekosistem & - & Literatur \\
\hline
\end{tabular}

\subsection{Pengolahan dan Analisis Data}

Alur teknis penelitian ini dibagi menjadi beberapa tahapan yaitu identifikasi garis pantai termasuk estimasi luas sedimentasi dan abrasi, identifikasi ekosistem di pesisir yang mengalami perubahan lingkungan, dan mendeskripsikan manfaat eksosistem yang telah teridentifikasi (gambar 2). Analisis data dilakukan secara deskriptif dan kuantitatif. Metode analisis deskriptif menggambarkan atau menjelaskan objek penelitian (masyarakat, analisis data sekunder, dan lain-lain) secara deskriptif. Adapun metode analisis kuantitatif digunakan untuk mengestimasi perubahan garis pantai, luas sedimentasi, dan abrasi di Pesisir Subang.

Pengolahan dan analisis data citra Landsat digunakan dalam mengidentifikasi pesisir yang mengalami sedimentasi dan abrasi. Tahapan ini dikelompokkan menjadi prapengolahan (preprocessing) dan pengolahan lanjutan termasuk analisis citra. Prapengolahan adalah proses koreksi citra secara geometris dan radiometris. Hasil pengolahan ini adalah data citra yang sudah memiliki posisi geografis yang sesuai dengan referensi di muka Bumi.

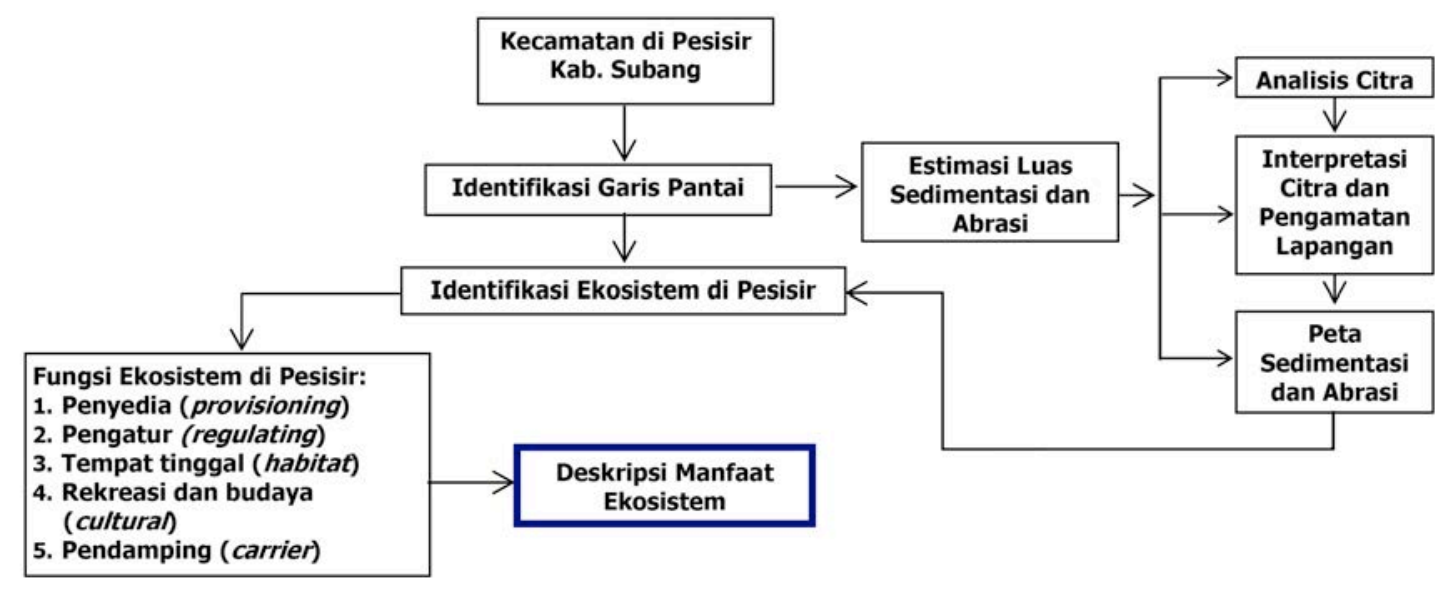

Gambar 2. Langkah Pengerjaan Teknis Penelitian 
Selanjutnya, data tersebut diproses menggunakan metode BILKO (UNESCO, 1999) untuk memberikan batasan antara darat dan laut secara jelas. Proses deliniasi dilakukan untuk menentukan garis pantai secara manual dan hasilnya dibandingkan dengan hasil pengamatan di lapangan. Ketelitian hasil perbandingan mengacu ketentuan Peraturan Badan Informasi Geospasial (BIG) No. 15 tahun 2014 pada tabel 8 terkait informasi ketelitian garis pantai. Adapun tabel 1 berisi informasi terkait ketelitian geometris peta rupa bumi (RBI) dan informasi ini digunakan sebagai rujukan pembuatan skala peta yang memuat garis pantai hasil delineasi. Proses tumpang susun garis pantai pada semua tahun pengamatan (1988, 1996, 2003, dan 2016) digunakan untuk mengestimasi luas sedimentasi dan abrasi. Sedimentasi diasumsikan jika garis pantai memaju dari satu tahun ke tahun berikutnya, sebaliknya abrasi diasumsikan mundurnya garis pantai. Populasi dalam pengambilan data kuesionar dan wawancara adalah sekumpulan orang dan/atau masyarakat sekitar, dimana lokasi tempat mereka tinggal mengalami perubahan erosi dan sedimentasi cukup signifikan. Berdasarkan karakteristik populasi tersebut maka teknik pengambilan sampel bersifat purposive. Jumlah sampel yang diperoleh bergantung dari masyarakat yang ditemui langsung di lapangan secara tidak sengaja.

\section{HASI L DAN PEMBAHASAN}

\subsection{I dentifikasi Perubahan Garis Pantai dan Ekosistem Pesisir}

Pesisir Kabupaten Subang memiliki morfologi pantai yang bervariasi. Sebagai ilustrasi, pantai sebelah barat Kabupaten Subang (Kec. Blanakan) lebih landai dibandingkan pantai sebelah timur (Kec. Cipunagara) (BPLHD Jabar, 2008). Kondisi alami menunjukkan perairan pantai Blanakan garis pantainya condong ke arah daratan dan berbentuk seperti teluk memungkinkan terjadinya proses sedimentasi yang tinggi. Sebaliknya di Legonkulon garis pantai daratan cenderung menjorok ke arah laut dan kondisi ini memungkinkan terjadinya abrasi (gambar 1). Observasi menunjukkan abrasi yang terjadi hampir di sepanjang pantai Subang. Kondisi ini diperparah dengan kerusakan hutan mangrove yang diubah menjadi lahan tambak. Abrasi tersebut terjadi di Muara Karang wilayah Legon Wetan hingga ke Pondok Bali, juga di daerah timur Subang sepanjang daerah Patimban (USAID Indonesia, 2006). Selain kedua proses tersebut, intrusi air laut juga termasuk dampak yang diakibatkan oleh perubahan garis pantai. Di Pesisir Subang diperkirakan intrusi air laut telah mencapai $\pm 10 \mathrm{~km}$ dari garis pantai. Pengambilan data sampel air tanah di Desa Muara (Kec. Blanakan) dan Desa Legonwetan (Kec. Legonkulon) menunjukkan karaktersitik air agak payau. Di Legonkulon nilai $\mathrm{DHL}<1500 \mu \mathrm{S} / \mathrm{cm}$ dan TDS $>1000 \mathrm{ppm}$, sedangkan nilai TDS di Muara mendekati 1000 ppm (Salim dkk., 2016).

Identifikasi perubahan garis pantai serta estimasi luas sedimentasi dan abrasi di sepanjang Pantai Subang diperoleh berdasarkan analisis citra di tahun 1988-2016. Penerapan metode BILKO pada citra memudahkan proses delineasi garis pantai. Proses deliniasi dilakukan pada peta skala 1:50.000, sehingga perbedaan antara garis pantai pada citra dan kondisi lapangan hendaknya memiliki nilai lebih kecil dari $20 \mathrm{~m}$ (BIG, 2014). Nilai penyimpangan garis pantai antara hasil pengolahan citra dan tracking di lapangan sebesar 10,9 m dan berkesesuian dengan ketentuan dari BIG (2014). Berdasarkan nilai tersebut dihitung Circular Error 90\% (CE90) dan hasilnya berkesesuaian ketelitian peta RBI kelas 1 dengan skala peta 1:100.000 (BIG, 2014). Estimasi perubahan garis pantai di Kabupaten Subang dari tahun 1988-2013 adalah 8,17 km, dimana panjang garis pantai di tahun 1988 sebesar 64,23 km dan tahun 2016 menjadi 72,40 km. Luas sedimentasi dan abrasi total di Pesisir Subang dalam rentang 
tahun tersebut diestimasi dengan nilai relatif seimbang yaitu 1723 ha (sedimentasi) dan 1496,5 ha (abrasi). Dibandingkan dengan semua kecamatan di Pesisir Subang, luas sedimentasi di Kecamatan Pusakanagara $(869,9$ ha) dan Blanakan $(725,4$ ha) memiliki nilai yang tinggi, sedangkan luas abrasi tertinggi berada di Kecamatan Legonkulon yaitu 885,8 ha (gambar 2).

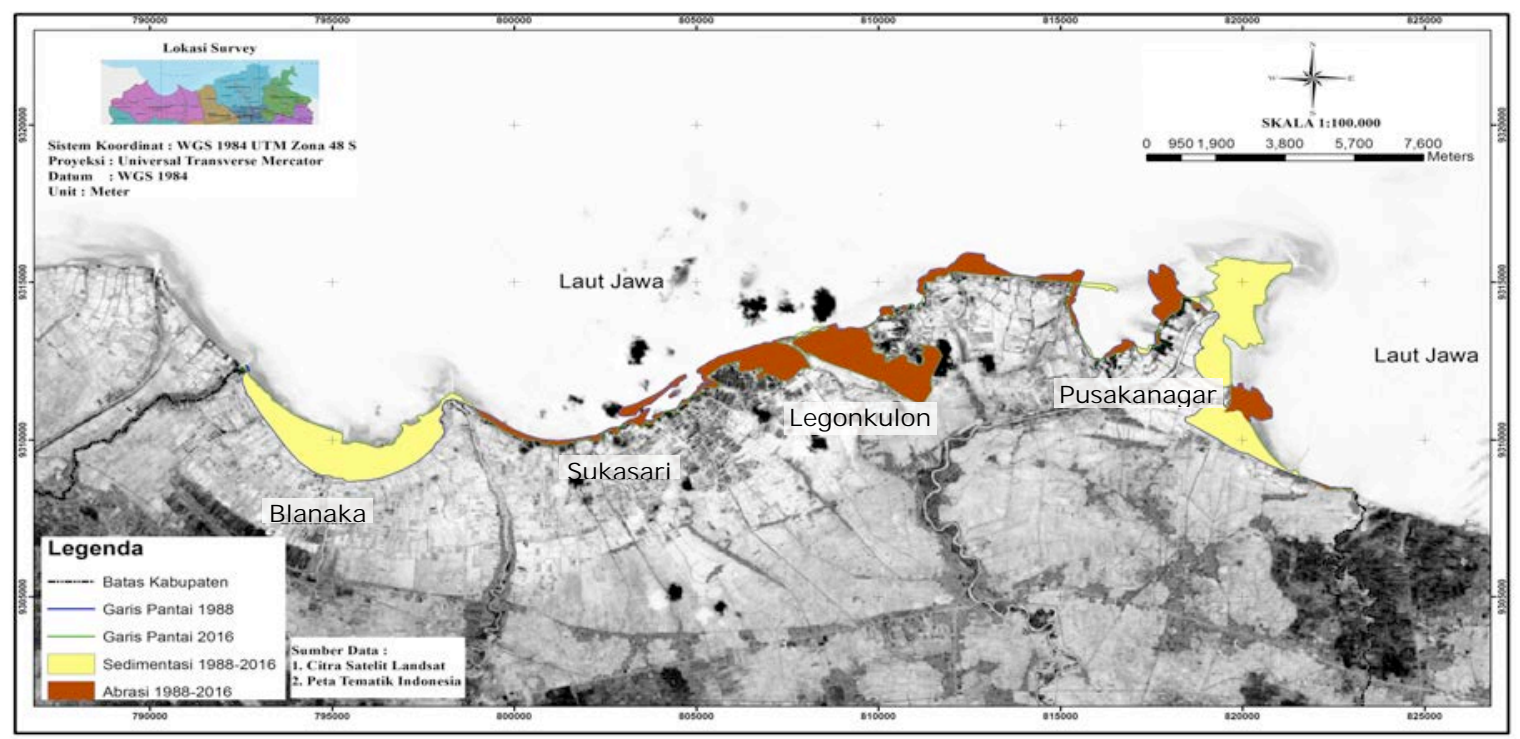

Gambar 2. Estimasi Perubahan Garis Pantai, Luas Sedimentasi, dan Abrasi antara Tahun 1988-2016 di Pesisir Subang

Cakupan tinjauan ekosistem pesisir dalam penelitian ini adalah terumbu karang, padang lamun, mangrove, estuari, dan tambak (tabel 2). Pemanfaatan ekosistem tambak saat ini di Pesisir Subang sangatlah intensif dan berada hampir di seluruh wilayah kecamatan pesisir. Urutan luas tambak dari terendah ke tertinggi berada di Kec. Patimban, Sukasari, Blanakan, dan Legokulon (DKP Subang, 2005). Tambak-tambak tersebut memanfaatkan karakteristik perairan pesisir untuk membudidayakan berbagai jenis ikan dan udang. Sejak tahun 1988 lahan tambak di Pesisir Subang terus bertambah seiring bertambahnya jumlah penduduk di wilayah pesisir (Fahrudin, 1996). Kondisi tersebut didukung oleh kebijakan pemerintah saat itu untuk memanfaatkan wilayah pesisir bagi kegiatan budidaya perikanan, padahal wilayah tersebut juga terdapat ekosistem mangrove. Seiring meluasnya pemanfaatan pesisir sebagai lahan tambak, kualitas mangrove juga mengalami tekanan yang tinggi sehingga berakibat degradasi kawasan mangrove di Pesisir Subang (Kawaroe, 2001; Bapeda Subang, 2001). Pengamatan di lapangan tahun 2017 menunjukkan kawasan mangrove dengan kondisi baik hanya terdapat di kecamatan Blanakan dan Legonkulon. Jika kondisi ini terus berlanjut akan berakibat terancamnya ekosistem mangrove di Pesisir Subang.

Terumbu karang merupakan salah satu kekayaan alam pesisir Indonesia yang diperkirakan luasnya saat ini semakin berkurang. Berdasarkan penelitian P3O LIPI kondisi terumbu karang saat ini hanya tinggal 6,2\% tutupan karang hidup dengan kondisi sangat baik di Indonesia. Terumbu dalam kondisi baik $23,72 \%$, kondisi rusak $28,30 \%$, dan kondisi rusak berat sebesar 41,78\% (Diposaptono, 2016). Data BPLHD Jabar (2008) menunjukkan luasan terumbu karang di Jawa Barat hanya terbatas di beberapa tempat yaitu Kab. Karawang, Subang dan Indramayu. Pesisir Subang memiliki kondisi oseanografis yang kurang memungkinkan tumbuhnya ekosistem terumbu karang. Tingginya aktivitas masyarakat pesisir dan muatan 
sedimen yang berasal dari banyak muara sungai menyulitkan terumbu karang untuk tumbuh dan berkembang (Suadi, 2001). Data menunjukkan terumbu karang yang terdapat di Pesisir Subang tidaklah besar dan hanya tersebar di perairan Kec. Blanakan sampai dengan Kec. Legonkulon, tepatnya di daerah Brobos (BPLHD Jabar, 2008; Kab. Subang, 2014) dan saat ini kawasan tersebut menjadi kawasan perlindungan (Kab. Subang, 2014) dan tidak dimanfaatkan secara ekonomi.

Tabel 2. I dentifikasi Perubahan Ekosistem di Pesisir Subang

\begin{tabular}{|c|c|c|c|c|c|c|}
\hline \multirow[t]{2}{*}{$\begin{array}{l}\text { Tinjauan } \\
\text { Ekosistem }\end{array}$} & \multirow[t]{2}{*}{ Deskripsi } & \multicolumn{4}{|c|}{$\begin{array}{l}\text { Kesesuaian dengan } \\
\text { Pesisir Subang } \\
\text { (Kecamatan)* }\end{array}$} & \multirow[t]{2}{*}{ Referensi } \\
\hline & & (1) & (2) & (3) & (4) & \\
\hline Terumbu Karang & $\begin{array}{l}\text { Kawasan lindung terumbu karang } \\
\text { berada di Pantai Bobos, Kec. } \\
\text { Legonkulon }\end{array}$ & & $\sqrt{ }$ & & & \multirow{5}{*}{$\begin{array}{l}\text { - BPLHD Jabar } \\
\text { (2008) } \\
\text { - Indrayanti } \\
\text { dkk. (2015) } \\
\text { - Kab. Subang } \\
\text { (2014) } \\
\text { - Rochana } \\
\text { (2010) } \\
\text { - Suadi (2001) }\end{array}$} \\
\hline Padang Lamun & $\begin{array}{l}\text { Tingginya pencemaran dan sedimen- } \\
\text { tasi di pesisir tidak kondusif bagi } \\
\text { pertumbuhan lamun }\end{array}$ & & & & & \\
\hline Estuari & $\begin{array}{l}\text { Lokasinya mencakup: } \\
\text { - tempat bermuaranya sungai } \\
\text { - aktivitas perikanan: Pangkalan } \\
\text { Pendaratan Ikan (PPI) dan } \\
\text { Pelabuhan Perikanan Pantai (PPP) } \\
\text { - aktivitas pelabuhan industri dan } \\
\text { domestik }\end{array}$ & $\sqrt{ }$ & $\sqrt{ }$ & $\sqrt{ }$ & $\sqrt{ }$ & \\
\hline Hutan Mangrove & $\begin{array}{l}\text { Luas total kawasan pantai berhutan } \\
\text { mangrove di Kec. Blanakan, Legon- } \\
\text { kulon, Sukasari, dan Pusakanagara } \\
\text { adalah } \pm 6,593 \text { ha. }\end{array}$ & $\sqrt{ }$ & $\sqrt{ }$ & $\sqrt{ }$ & $\sqrt{ }$ & \\
\hline Tambak & $\begin{array}{l}\text { Sistem budidaya tambak yang ada: } \\
\text { - kombinasi tambak dengan mangrove } \\
\text { - tambak tanpa mangrove } \\
\text { Lokasi tambak tersebar di Kec. Suka- } \\
\text { sari, Pusakanagara, Legonkulon, dan } \\
\text { Blanakan dengan luas } 2.283,76 \text { ha. }\end{array}$ & $\sqrt{ }$ & $\sqrt{ }$ & $\sqrt{ }$ & $\sqrt{ }$ & \\
\hline
\end{tabular}

* (1) Kec. Pusakanagara, (2) Kec. Legonkulon, (3) Kec. Sukasari, (4) Kec. Blanakan

Keberadaan padang lamun di pesisir berkaitan dengan sebaran terumbu karang. Saat ini di wilayah Pesisir Utara Jabar sudah jarang ditemukan ekosistem padang lamun dan hanya terdapat di daerah Sedulang Kab. Karawang dan Pulau Biawak di Kab. Indramayu (BPLHD Jabar, 2008). Keruhnya perairan dan tingginya tingkat pencemaran (limbah rumah tangga dan industri) merupakan faktor yang menghambat berkembangnya ekosistem padang lamun di pesisir Subang (Suadi, 2001). Pengamatan lapangan (2017) dan data-data sekunder lainnya tidak menunjukkan adanya kawasan padang lamun di Pesisir Subang (tabel 2).

Ekosistem estuari di Pesisir Subang juga memiliki aktivitas yang tinggi, terutama dalam perikanan (budi daya dan tangkap) serta pariwisata. Desa Pondok Bali di Kec. Legonkulon merupakan tempat wisata pantai yang ramai dikunjungi wisatawan, meskipun saat ini sudah terjadi erosi cukup tinggi (pengamatan lapangan, 2017). Beberapa fasilitas Pelabuhan Pelelangan Ikan (PPI) dengan berbagai tipe berada di Pesisir Subang. Secara skala regional PPI subang terbesar kedua setelah Pantai Pantura. Data DKP Subang (2005) menunjukkan 
ada tujuh lokasi PPI di berbagai desa pesisir yaitu: Desa Patimban (Pusakanagara), Desa Mayangan, Muara Ciasem, dan Pangarengan (Legonkulon), Desa Blanakan dan Cilamaya (Blanakan). Seiring berkembangnya kebutuhan dan aktivitas transportasi masyarakat di pesisir direncanakan akan dibangun pelabuhan bertaraf internasional di Patimban, Kecamatan Pusakanagara (Keputusan Menteri Perhubungan Republik Indonesia No. KP 87 2017 tentang Rencana Induk Pelabuhan Patimban). Pelabuhan ini diharapkan akan mendukung pelabuhan tanjung priok. Studi terbaru terkait kajian teknis pembangunan pelabuhan menunjukkan faktor gelombang dan sedimentasi adalah dua faktor utama yang harus diperhatikan dalam pemilihan jenis pelindung pantai (Jade dkk., 2016). Kondisi ini memperlihatkan aktivitas sedimentasi di muara Sungai Cipunegara cukup tinggi, seingga perlu adanya antisipasi dalam pengembangan pelabuhan di daerah tersebut.

Berbagai perubahan ekosistem di pesisir Subang didominasi oleh aktivitas manusia untuk memenuhi kebutuhan hidupnya. Tingkat kepekaan ekosistem terhadap aktivitas tersebut sangat bergantung dari respon ekosistem terhadap dampak yang terjadi. Respon ekosistem bervariasi dari yang peka sampai tidak peka, dan sangat bergantung pada karakteristik serta resistensi ekologi ekosistem tersebut. Pesisir Subang telah mengalami perubahan garis pantai akibat sedimentasi dan erosi di sepanjang pesisir. Ekosistem di pesisir merespon perubahan tersebut bergantung kepekaan ekologinya. Ekosistem terumbu karang dan padang lamun keberadaanya sangatlah terbatas, sedangkan ekosistem mangrove dan estuari cukup resisten, serta memiliki fungsi bervariasi (tabel 2). Adapun ekosistem buatan tambak berkembang sangat intensif dan untuk menyeimbangkan dampaknya terhadap ekologi dan pemanfaatannya secara ekonomi telah dikembangkan tumpang susun antara tambak dan mangrove (Rochana, 2010; Indrayanti dkk., 2015).

\subsection{Fungsi dan Manfaat Ekosistem di Pesisir Subang}

Saat ini ekosistem pesisir yang mendominasi di Subang adalah mangrove dan estuari (alami), serta tambak (buatan). Ketiga ekosistem tersebut saling berkaitan, yang mana mangrove dan tambak biasanya berada di kawasan estuari. Sehingga, fungsi dan manfaat dari ekosistem tersebut dapat dilihat dalam satu kesatuan. Berdasarkan fungsinya ekosistem pesisir dapat digolongkan menjadi lima fungsi (de Groot, dkk., 2002) yaitu penyedia (provisioning), pengatur (regulating), tempat tinggal (habitat), rekreasi dan budaya (cultura), dan pendamping (carrier).

Hutan mangrove adalah tipe hutan yang unik dan biasanya meluas di wilayah dengan muara sungai besar dan delta dengan aliran air yang mengandung banyak lumpur dan pasir (Nontji, 1993). Penelitian ini mendeskripsikan fungsi dan manfaat ekosistem mangrove dan estuari sebagai satu kesatuan (tabel 3). Kawasan mangrove umumnya berada di estuari, akan tetapi di estuari belum tentu terdapat lahan mangrove. Sehingga fungsi dan manfaat mangrove menjadi bagian dari fungsi dan manfaat estuari. Akan tetapi cakupan fungsi dan manfaat estuari lebih luas dibandingkan mangrove, salah satu contohnya adalah fungsi pendamping di estuari, yaitu transportasi antara darat dan laut. Fungsi ini tidak tercakup dalam fungsi dan manfaat mangrove.

Ekosistem mangrove memiliki fungsi dan manfaat ekologi sangat bervariasi di antaranya: sebagai pelindung pantai dari gempuran ombak, arus dan angin, sebagai tempat berlindung, berpijah dan daerah asuhan berbagai jenis biota, penghasil bahan organik yang sangat produktif (detritus), sumber bahan baku industri bahan bakar, pemasok larva ikan, udang dan biota laut lainnya, serta lokasi pariwisata (Bengen, 2000). Akan tetapi, fungsi dan 
manfaat ekologi mangrove di pesisir Subang telah mengalami degradasi sejalan intensifnya aktivitas pembangunan masyarakat setempat (Saridewi, 2003; Rochana, 2010; Indrayanti dkk., 2015). Data Badan Perencanaan Daerah Kabupaten Subang (dalam Rochana, 2010) menunjukkan penurunan lahan mangrove seluas 2087,7 ha dalam periode 1988-1992.

Tabel 3. Fungsi dan Manfaat dari Ekosistem di Pesisir Subang

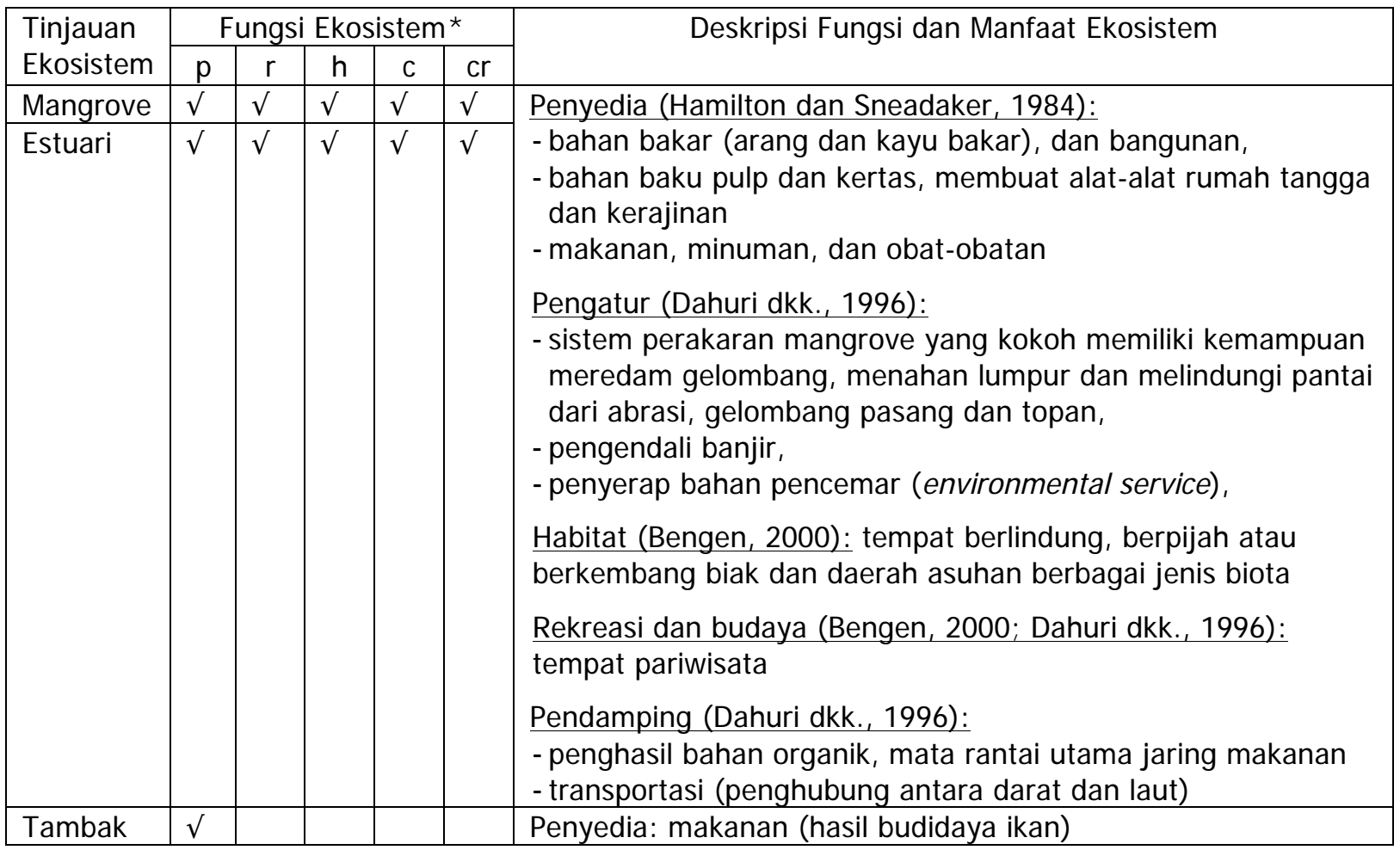

* $\mathrm{p}=$ provisioning, $\mathrm{r}=$ regulating, $\mathrm{h}=$ habitat, $\mathrm{c}=$ culture, $\mathrm{cr}=$ carrier

Kondisi penurunan ini berhubungan dengan perluasan areal tambak di wilayah Pesisir Subang. Tahun 1992-1995 Dinas Kehutanan melakukan program tambak tumpang sari (silvofishery atau minawana), penggabungan antara tambak dan mangrove, dan berhasil menambah luas lahan mangrove seluas 3074,3 ha (Dinas Kelautan dan Perikanan Kabupaten Subang, 2003). Selanjutnya, data BPLHD Jabar (2008) menunjukkan luas hutan mangrove di Pesisir Subang sekitar 7346 ha dengan kondisi level sedang. Pengamatan lapangan saat ini (2017) menunjukkan hutan mangrove di bagian pantai timur Subang (Pusakanagara) telah habis. Di wilayah barat (Blanakan dan Legonkulon) masih memiliki hutan mangrove yang relatif baik dan pemanfaatannya tergabung dengan tambak (minawana). Pemanfaatan ini umumnya berada di kawasan hutan mangrove yang dikelola Dinas Perhutani dengan aturan pembagian $80 \%$ mangrove dan $20 \%$ empang/tambak (Perhutani, 1995). Namun, kondisi lapangan saat ini menunjukkan pemanfaatan tambak yang melebihi lahan mangrove, selain itu beberapa petambak yang berpendapat sistem akar mangrove mengurangi hasil budidaya tambak yang ada (hasil wawancara penduduk di Legonkulon).

Terlepas permasalahan lahan mangrove versus tambak, wilayah pesisir Subang memiliki potensi fungsi dan manfaat lain yang sedang dikembangkan. Saat ini di kawasan estuari Patimban (Kec. Pusakanagara) sedang dibangun pelabuhan internasional sebagai pendukung pelabuhan Tanjung Priok, Jakarta. Selain kondisi oseanografi yang sesuai, rute yang berdekatan dengan pelabuhan internasional dan tujuan pasar internasional. Pelabuhan ini 
nantinya berperan sebagai tempat alih muat peti kemas, cargo, penumpang internasional maupun nasional. Pembangunan pelabuhan akan dilakukan dalam tiga tahapan: pendek (2017-2019), menengah (2017-2026), dan panjang (2017-2036). Estimasi kenaikan Produk Domestik Regional Bruto (PDRB) Kabupaten Subang dengan dibangunnya pelabuhan baru diprediksi rata-rata pertumbuhan 6,4\% sampai dengan tahun 2040 (Keputusan Menteri Perhubungan Republik Indonesia Nomor KP 87, 2017). Nilai manfaat atas alih fungsi estuari alami menjadi wilayah transportasi hendaknya diperhitungkan secara berimbang. Kerusakan yang akan terjadi seiring pembangunan pelabuhan hendaknya dimasukkan dalam perhitungan pengembangan pelabuhan sehingga nantinya dapat diketahui berapa besar dana pengelolaan yang diperlukan untuk keberlanjutan fungsi pelabuhan tersebut.

\section{KESIMPULAN}

Penelitian ini mengidentifikasi perubahan garis pantai dan perubahan ekosistem di Pesisir Subang. Estimasi perubahan garis pantai dibuat berdasarkan analisis citra Landsat dengan menggunakan metode tumpang susun berdasarkan data tahun 1988, 1996, 2003, dan 2016. Deskripsi fungsi dan manfaat dari masing-masing ekosistem dibuat berdasarkan analisis data dan literatur secara deskriptif dan kuantitatif. Estimasi perubahan garis pantai dari tahun 1988-2013 sebesar 8,17 km dan perubahan tersebut didominasi oleh proses sedimentasi di Kecamatan Pusakanagara (869,9 ha) dan Blanakan $(725,4$ ha), sedangkan abrasi di Kecamatan Legonkulon (885,8 ha). Kawasan estuari dan mangrove adalah ekosistem dengan tingkat aktivitas pembangunan tertinggi dan terbesar yang mengalami perubahan di Pesisir Subang. Kondisi ini mengakibatkan terjadinya penurunan terhadap fungsi ekologi dari ekosistem-ekosistem tersebut. Adapun ekosistem tambak dibuat dengan mengubah lahan mangrove yang hanya berfungsi untuk memenuhi kebutuhan pangan. Hasil ini menunjukkan pentingnya valuasi ekonomi lahan mangrove versus budidaya tambak di Kec. Legonkulon dan kawasan estuari sebagai sarana transportasi di Kec. Pusakanagara. Memperhitungkan fungsi ekonomi dan ekologi dari ekosistem secara berimbang dapat dibantu dengan valuasi ekonomi atas ekosistem tersebut. Hasilnya akan dapat mendukung terciptanya pengelolaan wilayah Pesisir Subang secara berkelanjutan.

\section{DAFTAR PUSTAKA}

Bappeda Subang. (2010). Laporan Akhir: Kajian Pengembangan Minapolitan di Pantura Kabupaten Subang Tahun Anggaran 2010. Subang.

Bengen, D.G. (2000). Pedoman Teknis Pengenalan dan pengelolaan Ekosistem Mangrove. Bogor : Pusat Kajian Sumberdaya Pesisir dan Lautan. Institut Pertanian Bogor.

BPLHD Jabar. (2008). Status Lingkungan Hidup Tahun 2008: Bab 7 Laut dan Pesisir. http://www.bplhdjabar.go.id, Badan Pengelolaan Lingkungan Hidup Daerah, Bandung.

Dahuri, R., Rais, J., Ginting, S.P., dan Sitepu, M. J. M. J. (1996). Pengelolaan Sumberdaya Wilayah Pesisir dan Lautan Secara Terpadu. Jakarta: PT. Pradnya Paramita.

De Groot, R.S., Wilson, M.A., dan Boumans, R.M.J . (2002). A typology for the classification, description and valuation of ecosystem functions, goods and services. Ecol. Econ. 41, 393- 408.

DKP Subang. (2003). Pemetaan Potensi Kelautan dan Perikanan (ATLAS) Kabupaten Subang. Kerjasama Pemerintah Kabupaten Subang dengan Fakultas Perikanan dan IImu Kelautan, Institut Pertanian Bogor. 
DKP Subang. (2005). Evaluasi Program Pembangunan Kelautan dan Perikanan Kabupaten Subang Tahun 2004. Subang.

Diposaptono, S. (2016). Membangun Poros Maritim Dunia Dalam Perspektif Tata Ruang Laut. Perpustakaan Nasional. ISBN: 978-979-1291-55-2.

Fahrudin, A. (1996). Analisis Ekonomi Pengelolaan Lahan Pesisir Kabupaten Subang, Jawa Barat [tesis]. Bogor: Sekolah Pascasarjana, Institut Pertanian Bogor.

Fauzi, A. (2004). Ekonomi Sumberdaya Alam dan Lingkungan. Teori dan Aplikasi. Jakarta: PT. Gramedia Pustaka Utama.

Indrayanti, M.D., Fahrudin, A., dan Setiobudiandi, I. (2015). Penilaian Jasa Ekosistem Mangrove di Teluk Blanakan Kabupaten Subang. Jurnal IImu Pertanian Indonesia (JIPI). Volume 2, No.2 Agustus 2015.

Jade, R.M.R, Perbani, N.M.R.R.C., dan Handiani, D.N. (2016). Analisis Efektivitas Bangunan Pelindung Pelabuhan Patimban dan Pantai Sekitar Melalui Tinjauan Hidro-Oseanografi. Reka Geomatika Vol. 2016, Jurusan Teknik Geodesi, Institut Teknologi Nasional, Bandung.

Kawaroe, M. (2001). Kontribusi Ekosistem Mangrove terhadap Struktur Komunitas Ikan di Pantai Utara Kabupaten Subang, Jawa Barat. Jurnal Pesisir dan Lautan. Vol.3:3, pp.13, Bogor.

Keputusan Menteri Perhubungan Republik Indonesia Nomor KP 87. (2017). Rencana Induk Pelabuhan Patimban Provinsi Jawa Barat

Nontji, A. (1993). Laut Nusantara. Cetakan Kedua. Djambatan. Jakarta.

Kabupaten Subang (2014). Peraturan Pemerintah Kabupaten Subang No. 3, 2014 tentang Rencana Tata Ruang Wilayah Kabupaten Subang Tahun 2011-2031. Subang.

Pemerintah Provinsi Jawa Barat (Pemprov Jabar). (2017). Peta Jawa Barat. Dipetik 30 Maret, 2017 dari http://www.jabarprov.go.id/index.php/pages/id/99

Peraturan Badan Informasi Geospasial. (2014). Pedoman Teknis Ketelitian Peta Dasar. Badan Informasi Geospasial. Bogor.

Perhutani (1995). Pengelolaan Ekosistem Mangrove dengan Pendekatan Sosial Ekonomi pada Masyarakat Desa Pesisir Pulau Jawa. Prosiding Seminar V; Ekosistem Mangrove, Jember 3-6 Agustus 1994: 35-42. Jakarta: Kontribusi MAB Indonesia No. 72-LIPI.

Rochana, E. (2010). Analisis Kebijakan Pengelolaan Sumberdaya Pesisir dan Laut Dalam Penangggulangan Kemiskinan di Kabupaten Subang Jawa Barat[disertasi]. Bogor: Sekolah Pasca Sarjana, Institut Pertanian Bogor.

Salim, A.G., Siringoringo, H.H., dan Narendra, B.H. (2016). Pengaruh Penutupan Mangrove Terhadap Perubahan Garis Pantai dan Intrusi Air Laut di Hilir DAS Ciasem dan Cipunegara, Kabupaten Subang. Jurnal Manusia dan Lingkungan, Vol.23, No.3. Pusat Penelitian dan Pengembangan Hasil Hutan.

Saridewi, T.R. (2003). Studi Pembangunan Ekonomi Wilayah Pesisir di Kabupaten Subang[tesis]. Bogor: Sekolah Pascasarjana, Institut Pertanian Bogor.

Suadi (2007). Rancang Bangun Kebijakan Pembangunan Wilayah Pesisir Berkelanjutan Secara Partisipatif di Kabupaten Subang, Disertasi. Bogor: Sekolah Pascasarjana, Institut Pertanian Bogor.

UNESCO (1999). Applications of Satellite and Airborne Image Date to Coastal Management. Coastal region and small island papers 4, UNESCO, Paris, vi + $185 \mathrm{pp}$.

USAID Indonesia (2006). Program Daerah Aliran Sungai dan Lingkungan Hidup Kabupaten Subang. Environmental Service Program, DAI Project Number : 5300201.

USGS Global Visualization Viewer. (2017). USGS science for a changing world. Dipetik 30 Maret, 2017 dari http://glovis.usgs.gov/ 